\title{
FGF8 is Essential for Functionality of Induced Neural Precursor Cell-derived Dopaminergic Neurons
}

\author{
Mi-Sun Lim ${ }^{1,2}$, Soo Young Lee ${ }^{3}$, Chang-Hwan Park ${ }^{1,2,3}$ \\ ${ }^{1}$ Graduate School of Biomedical Science and Engineering, ${ }^{2}$ Hanyang Biomedical Research Institute, \\ ${ }^{3}$ Department of Microbiology, College of Medicine, Hanyang University, Seoul, Korea
}

Induced neural precursor cells (iNPCs) are one source of transplantable dopaminergic neurons used in cell therapy for Parkinson's disease. In the present study, we demonstrate that iNPCs can be generated by transducing Brn2, Ascll, Myt1L and Bcl-xL in a culture supplemented with several mitogens and subsequently can be differentiated to dopaminergic neurons (DA). However, studies have shown that iDA and/or iNPC-derived DA neurons using various conversion protocols have low efficiency. Here, we show that early exposure of FGF8 to fibroblasts efficiently improves differentiation of DA neurons. So our study demonstrates that FGF8 is a critical factor for generation of iNPC-derived DA neurons.

Keywords: Direct conversion, FGF8, Dopamine neuron, iNPC

\section{Introduction}

Direct conversion is a process by which somatic cells are reprogrammed into tissue-specific cells, such as induced neural (iN) cells, spinal motor neurons, and dopaminergic (DA) neurons, using a combination of tissue-related factors and mitogens (1-3). Recent studies have described the direct conversion of somatic cells into induced neural precursor cells (iNPCs) and induced dopaminergic neurons (iDA) (4-6); however, the conversion efficiency to iDA in these studies was low. Caiazzo et al. (2) and Pfisterer et al. (3) showed that mouse and human fibroblasts can

\footnotetext{
Accepted for publication August 12, 2015, Published online November 30, 2015 Correspondence to Chang-Hwan Park

Lab. of Neural Stem Cell Biology, Graduate School of Biomedical Science \& Engineering and Department of Microbiology, College of Medicine, Hanyang University, 222 Wangsimni-ro, Seongdong-gu, Seoul 04763, Korea

Tel: +82-2-2220-0646, Fax: +82-2-2220-2422

E-mail: chshpark@hanyang.ac.kr

(c) This is an open-access article distributed under the terms of the Creative Commons Attribution Non-Commercial License (http://creativecommons.org/ licenses/by-nc/4.0/), which permits unrestricted non-commercial use, distribution, and reproduction in any medium, provided the original work is properly cited.
}

be directly converted to DA neurons using transcription factors, such as Nurr1, Ascl1, Lmxla and Foxa2. These studies did not supplement culture media with fibroblast growth factor 8 (FGF8), but other research groups [e.g., Kim (7) and Liu (8)] have reported successful production of iDA neurons by adding FGF8 to media.

FGF8 has been implicated in early vertebrate brain patterning, and inhibition of its expression is associated with absence of the entire mesencephalic and cerebellar primordia and early embryonic death $(9,10)$. FGF8 is capable of binding to all four FGF receptors, with different affinities (11). When the growth factor binds to its receptor, phosphorylation of extracellular signal-regulated kinase 1/2 (ERK1/2) usually occurs and in turn activates the RAS-MAPK intracellular pathway $(12,13)$. Several neurotrophic factors, including sonic hedgehog (shh) and FGF8, are critical to the specification and differentiation of midbrain DA neuron development (14). Additionally, FGF8 immunoreactivity levels in the substantia nigra have been found to be significantly lower among Parkinson's disease (PD) patients than in age-matched controls (15), although there is no evidence that this is a primary event in PD. It is therefore reasonable to assume that FGF8 may have dual roles in survival of iNPCs and maturation of 
iNPC-derived DA neurons.

Kim et al. (7) suggested that FGF8 is critical to promote iDA neuron generation from fibroblasts; however, their process directly reprogrammed fibroblasts into iDA neurons without passing through the NPC stage. Thus, we would like to evaluate whether FGF8 is in fact essential for iNPC conversion process and DA neuron generations passing through the NPC stage. To address this, we investigated the generation of iNPCs and DA neurons in the presence or absence of FGF8. Here, we demonstrate that early and continuous exposure of FGF8 to fibroblasts and iNPCs promotes maturation of iNPC-derived DA neurons.

\section{Materials and Methods}

\section{Fibroblast isolation}

Animals were housed and treated according to the Institutional Animal Care and Use Committee (IACUC) guidelines of Hanyang University. Embryonic fibroblasts (REF) from Sprague-Dawley rats (DaeHan BioLink, Seoul, Korea) were isolated from embryonic day 14 embryos after removing the head, spinal cord, and all internal organs, including the gonads. Fibroblasts were cultured in highglucose Dulbecco's modified Eagle's medium (DMEM; Invitrogen, Carlsbad, CA, USA) supplemented with $10 \%$ fetal bovine serum (FBS; Invitrogen), $0.1 \mathrm{mM}$ nonessential amino acids (Invitrogen), $0.1 \mathrm{mM} \quad \beta$-mercaptoethanol (Sigma-Aldrich, St. Louis, MO, USA), $2 \mathrm{mM}$ L-glutamine (Sigma-Aldrich), and 1\% penicillin-streptomycin (Invitrogen).

\section{Retroviral production}

Retroviral constructs for Brn2 (B), Ascl1 (A), Myt1l (M), Bcl-xL (X), Nurr1 (N), and Foxa2 (F) were constructed by engineering the appropriate DNA fragments into the retroviral vector, $\mathrm{pCL}$ (16). The retroviral vectors were transfected into 293GPG packaging cells using Lipofectamine 2000 (Invitrogen). Supernatants containing viral particles were harvested 72 hours after transfection.

\section{iNPCs generation and isolation}

iNPCs generation was performed as previously described (17). Briefly, for generation of iNPCs, fibroblasts were seeded on gelatin-coated culture dishes $\left(0.5 \sim 1 \times 10^{6} / 100\right.$ $\mathrm{cm}$ dish). The next day, the cells were transduced with four retroviruses (BAMX). After 16 20 hours, the culture media were changed to two different media: 1) fresh fibroblast media containing $100 \mathrm{ng} / \mathrm{mL}$ human fibroblast growth factor 8 (FGF8; PeproTech, Rocky Hill, NJ, USA) and 2) fresh media that did not contain FGF8. After two days, transduced cells were placed into neural induction media [NIM: N2 medium supplemented with $20 \mathrm{ng} / \mathrm{mL}$ basic fibroblast growth factor (bFGF; R\&D Systems, Minneapolis, $\mathrm{MN}$, USA), $100 \mathrm{U} / \mathrm{mL}$ recombinant human leukemia inhibitory factor (EMD Millipore, Billerica, MA, USA), $2 \mu \mathrm{g} / \mathrm{mL}$ doxycycline (Sigma-Aldrich) and with/without $100 \mathrm{ng} / \mathrm{mL}$ FGF8] and the culture media were changed every other day thereafter. Two days after initiating NIM culture conditions, cells were transferred to six-well culture dishes pre-coated with $15 \mu \mathrm{g} / \mathrm{mL}$ poly-L-ornithine (PLO; Sigma-Aldrich) and $1 \mu \mathrm{g} / \mathrm{mL}$ fibronectin (FN; SigmaAldrich) and maintained in NIM. After approximately two to three weeks, cell morphologies changed to neural stemlike cells, as evidenced by small cell size and bipolar morphology. Formation of cell clusters was also observed.

\section{Dopamine neuron generation from fibroblast-derived iNPCs}

To generate dopaminergic neurons, iNPCs were transferred onto coverslips (Bellco Glass, Vineland, NJ, USA) pre-coated with PLO/FN. After one day, iNPCs were transduced for two hours with dopaminergic neuron-related factors, Nurr1 and Foxa2 retroviruses, which were cultured overnight in NIM and differentiated the following day in media containing $0.2 \mathrm{mM}$ ascorbic acid (AA; Sigma-Aldrich), $20 \mathrm{ng} / \mathrm{mL}$ brained-derived neurotrophic factor (BDNF; R\&D Systems), $20 \mathrm{ng} / \mathrm{mL}$ glial cell-line-derived neurotrophic factor (GDNF; R\&D Systems), and 250 $\mu \mathrm{g} / \mathrm{mL}$ dibutyryl cAMP (Sigma-Aldrich) in N2 medium.

Table 1. Primary antibody information

\begin{tabular}{llll}
\hline \multicolumn{1}{c}{ Antibody } & Dilution & \multicolumn{1}{c}{ Company } & \multicolumn{1}{c}{ Location } \\
\hline Polyclonal antibody (Rabbit) & & & \\
$\quad$ Nestin \#130 & $1: 50$ & Provided by Dr. R. McKay & \multicolumn{1}{c}{ NIH, Bethesda, MD, USA } \\
Tyrosine hydroxylase (TH) & $1: 5000$ & Pel-Freez Biologicals & $\begin{array}{l}\text { Rogers, AR, USA } \\
\text { Sox2 }\end{array}$ \\
$\begin{array}{l}\text { Monoclonal antibody (Mouse) } \\
\text { Ki67 }\end{array}$ & $1: 500$ & Chemicon & Temecula, CA, USA \\
Neuron-specific class III $\beta$-tubulin (Tuj1) & $1: 100$ & Novocastra Laboratories & Newcastle, UK \\
\hline
\end{tabular}




\section{Immunostaining of cultured cells}

Immunostaining of cultured cells was performed as previously described (18). Cells were photographed using an epifluorescence microscope (Leica Microsystems, Wetzlar, Germany). Measurement of tyrosine hydroxylase (TH) fiber length was computed with the Leica Application Suite (LAS) image analysis package. Primary antibody information is summarized in Table 1.

\section{Cell counting and statistical analyses}

Cell counting was performed on a random selection of $5 \sim 10$ uniform microscopic fields/wells, with $3 \sim 4$ wells per experimental condition. All values were confirmed with at least three independent experiments. Data were expressed as mean \pm SEM. When more than two groups were compared, a paired $t$-test was performed using SigmaPlot for Windows, version 10.0 (Systat Software GmbH, Erkrath, Germany).

\section{Results}

\section{FGF8 did not influence the proliferation efficiency in cultured iNPCs}

Recently, our study has shown that NPCs can be successfully generated from fibroblasts transduced with BAMX (17). Briefly, after 16 20 hours of transduction, all media were changed to $10 \%$ DMEM (-FGF8) or 10\% DMEM (+FGF8); two days later, NIM (-FGF8) or NIM (+FGF8) media were applied for neural induction and NPC expansion, after which rat fibroblasts transformed into small and slender cells. Cells with morphologies consistent with a neural lineage were generated within two weeks, and they actively proliferated into cluster-forming cells after another two weeks of growth in culture conditions, as schematized in Fig. 1A. There were no significant differences in the formation of NPC-like cluster cells without or with FGF8 (Fig. 1B and C).

To investigate whether FGF8 has a positive effect on iNPCs proliferation, we compared the characteristics of
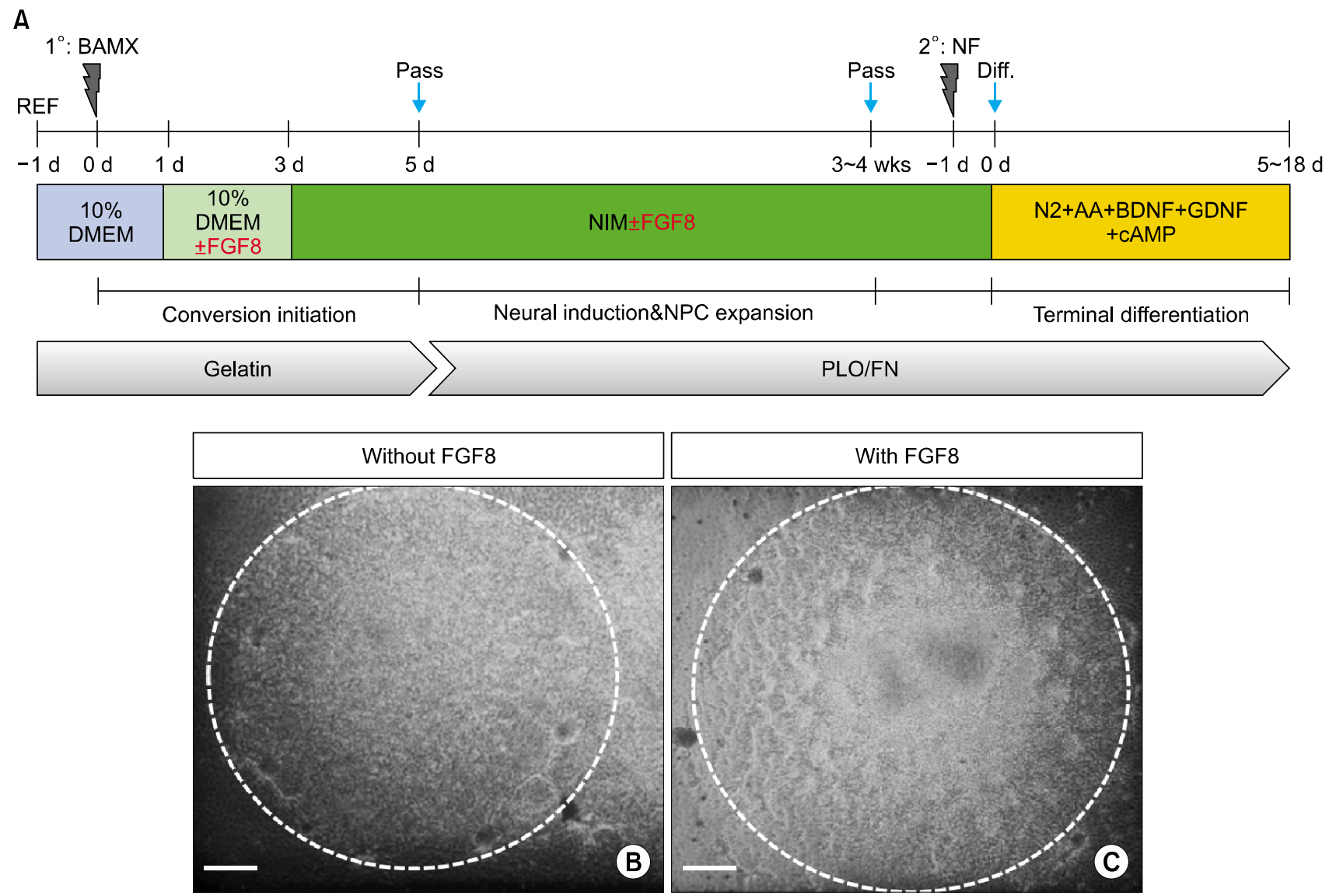

Fig. 1. Generation of iNPCs from rat embryonic fibroblasts in two culture conditions; (A) Schematic diagram depicting the timeline of iNPCs during the conversion process; (B, C) Morphology of iNPCs in the absence of FGF8 (B) and presence of FGF8 (C); Four weeks after the conversion period, cluster-forming cells were observed (B, C, white dotted circle). Scale bar $=100 \mu \mathrm{m}$. 
iNPCs derived from with or without FGF8. After dissociating the mechanically selected clusters into individual cells, they were transferred to PLO/FN-coated dishes and expanded by passaging them every $5 \sim 7$ days. The iNPC proliferation rate did not differ between these two groups [Fig. 2: with FGF8 and without FGF8, nestin $>70 \%$, sox2 $>70 \%$, ki67 $>70 \%$, each passage (p2, p4, p6)]. Collectively, these findings suggest that FGF8 does not contribute to iNPC proliferation efficiency.

FGF8 is essential for induction and maturation of DA neurons

Next, we evaluated the ability of iNPCs to differentiate into DA neurons. To this end, we transduced iNPCs (derived from with FGF8 and without FGF8) with DA neuron-specific factors, Nurr1 and Foxa2. After differentiation 5 and 18 days, passaged p1 and p2 cells revealed that the numbers of $\mathrm{TuJ} 1+$ cells and $\mathrm{TH}+$ cells increased in the presence of FGF8 by immunocytochemistry analysis (Fig. 3A and B: TuJ1+ cells: P1-D5 vs. P1-D18; 35.3 $\pm 1.3 \%$ vs. $35.6 \pm 3.6 \%$; $\mathrm{P} 2-\mathrm{D} 5$ vs. $\mathrm{P} 2-\mathrm{D} 18 ; 32.6 \pm 1.3 \%$ vs. $31.3 \pm 2.7 \%$; $\mathrm{TH}+$ cells: $\mathrm{P} 1-\mathrm{D} 5$ vs. P1-D18; $25.3 \pm 1.3 \%$ vs. $28.6 \pm 1.8 \%$; P2-D5 vs. P2-D18; $24.3 \pm 2.0 \%$ vs. $25.6 \pm 3.7 \%$ ) compared to the absence of FGF8 (Fig. 3C and D: TuJ1+ cells: P1-D5 vs. P1-D18; $8.6 \pm 1.8 \%$ vs. $4.6 \pm 2.0 \%$; P2-D5 vs. P2-D18; $8.3 \pm 1.8 \%$ vs. $2.6 \pm 1.0 \%$; $\mathrm{TH}+$ cells: P1-D5 vs. P1-D18;
A

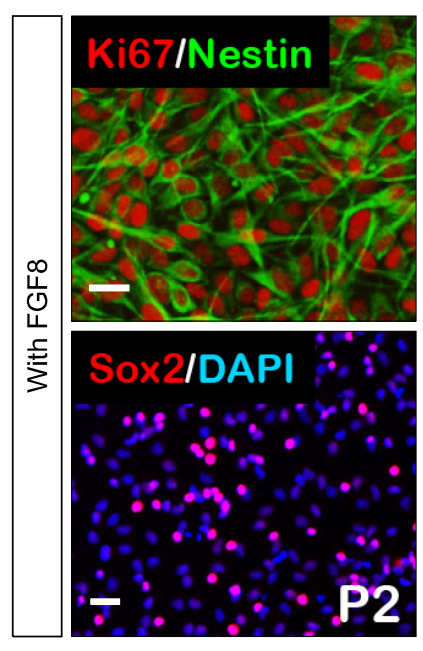

C

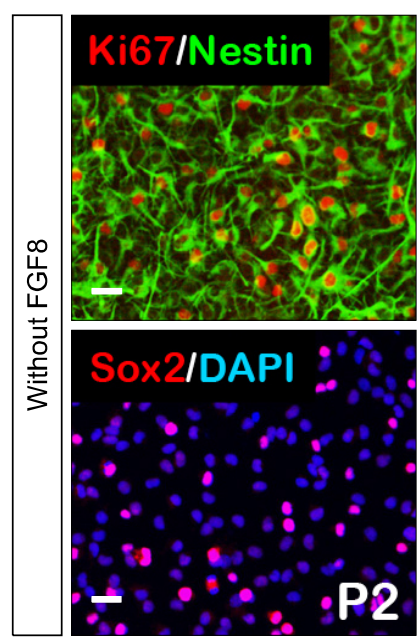

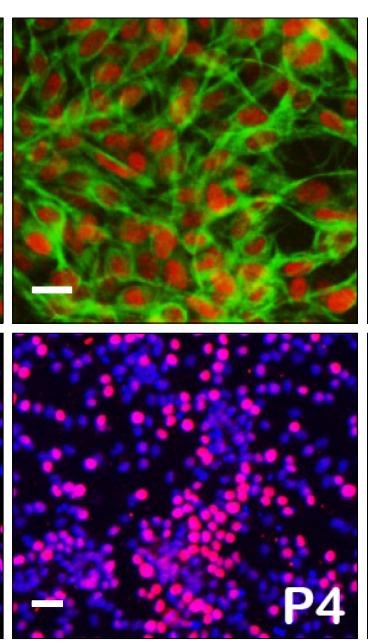
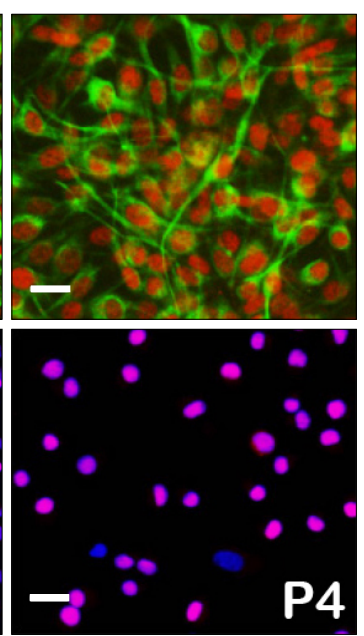

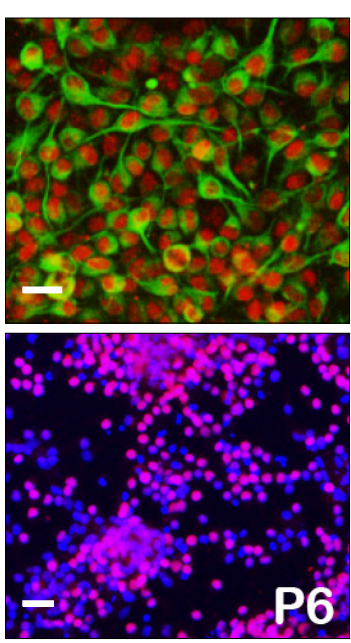

B
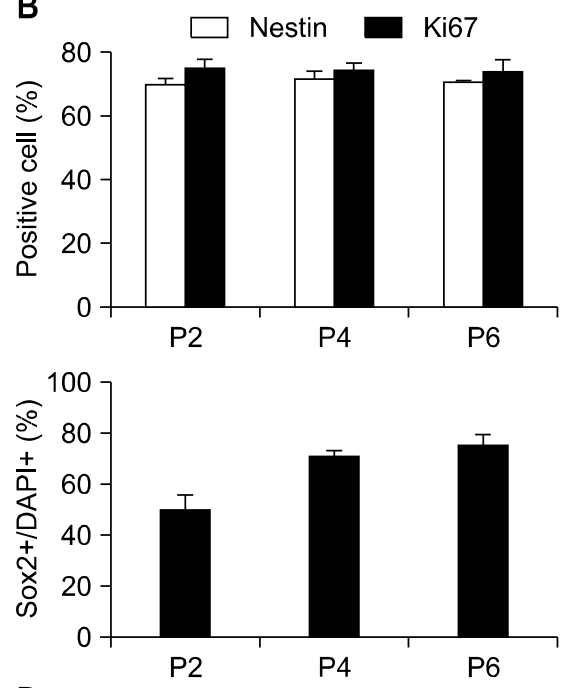

D
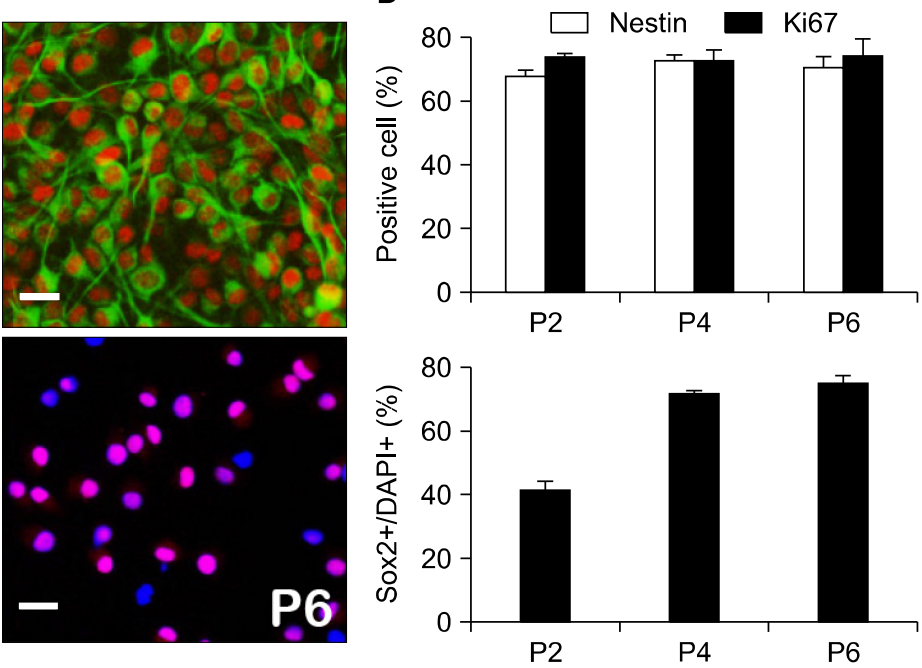

Fig. 2. Characterization of iNPCs between two culture conditions: (A, B) Cultured iNPCs in the presence of FGF8 were stably expandable without loss of self-renewing potentials. iNPCs were cultured for more than six passages and were analyzed using immunocytochemistry analyses with the proliferating marker, ki67, neural precursor marker nestin, and sox2 on the last day of each passage. (C, D) Cultured iNPCs in the absence of FGF8 were also not associated with significant changes in the percentage of iNPCs compared to FGF8-supplemented culture. Error bars denote the standard error of the mean (SEM, $\mathrm{n}=3$ ). Scale bar $=20 \mu \mathrm{m}$. 


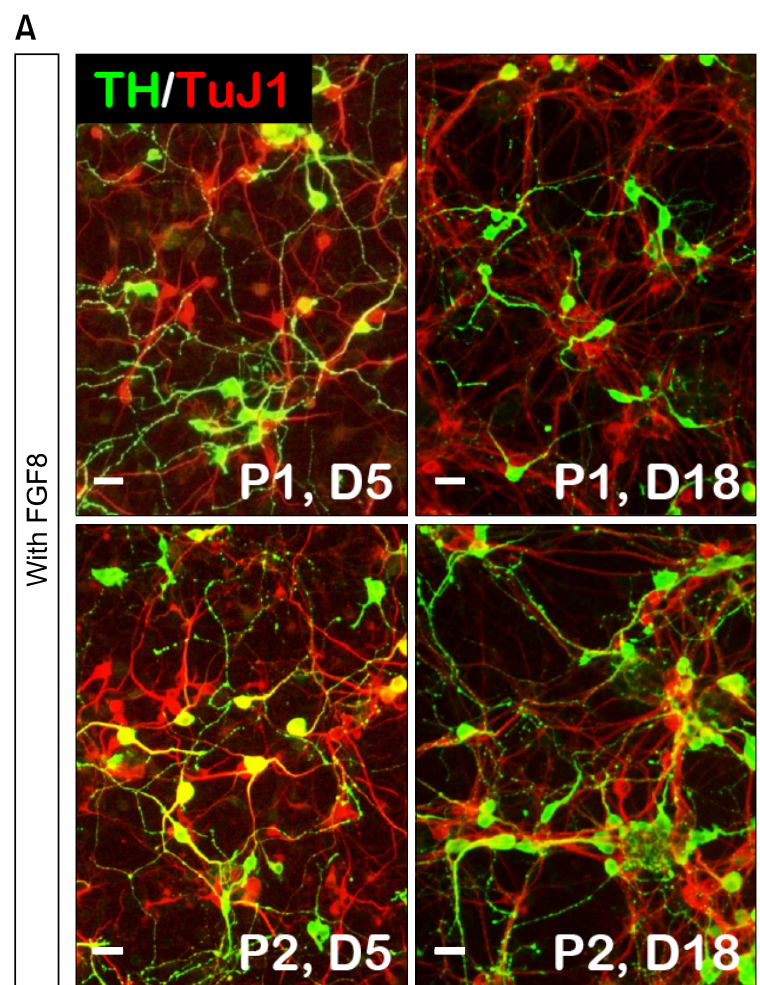

B
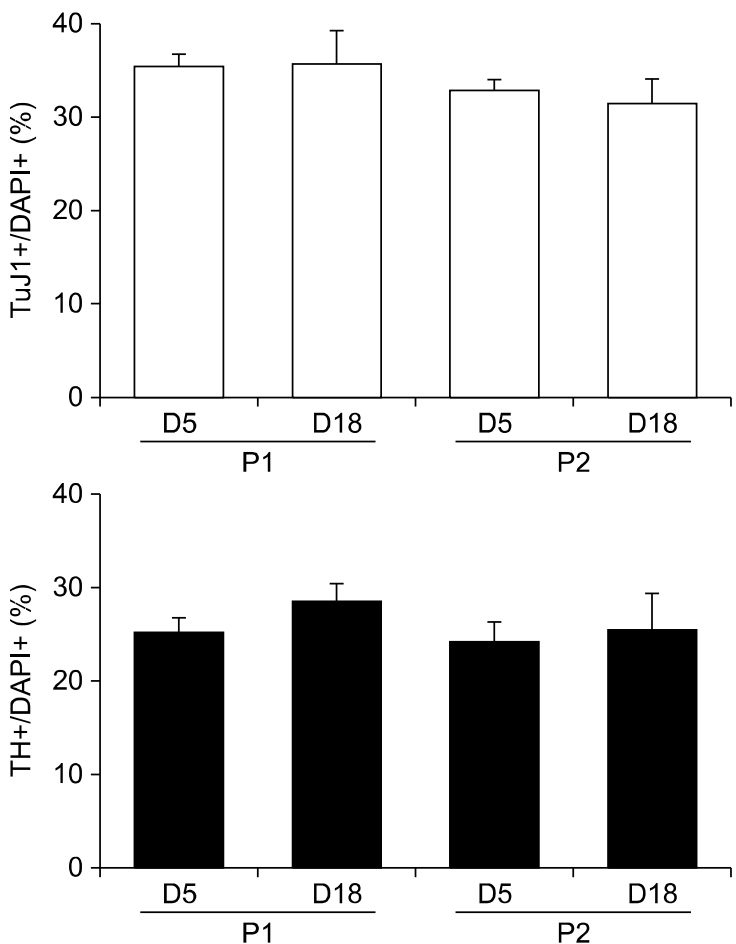

C

D
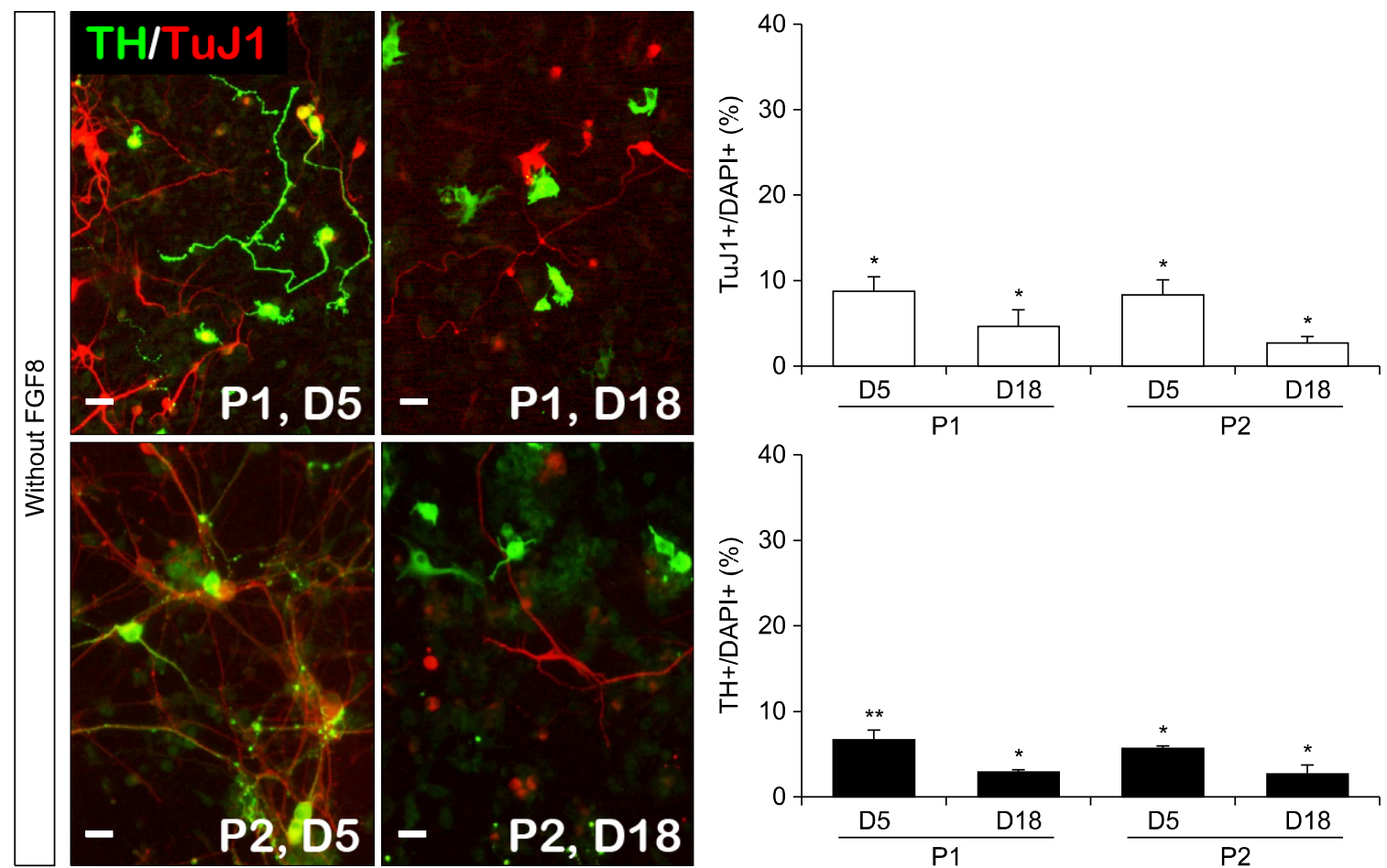

Fig. 3. Functional DA neurons enhanced by FGF8 treatment during the iNPC generation period: (A, B) Cultured DA neurons in the presence of FGF8 were more functional than TuJ1 + and $\mathrm{TH}+$ neurons after short- and long-term differentiation ( 5 and 18 days) without loss of Tul 1 or TH + cells. (C, D) Cultured DA neurons in the absence of FGF8 were observed to include TuJ1+ and TH+ cells; however, most of cells had an immature morphology, and the numbers of $\mathrm{Tu} 1+$ and $\mathrm{TH}+$ cells decreased over long-term differentiation compared to those supplemented with FGF8. Error bars denote the standard error of the mean (SEM, $\mathrm{n}=3$ ). Scale bar $=20 \mu \mathrm{m} .{ }^{*} \mathrm{p}<0.05,{ }^{* *} \mathrm{p}<0.001$ compared to the FGF8 condition. 
$6.3 \pm 1.3 \%$ vs. $2.6 \pm 0.5 \%$; P2-D5 vs. P2-D18; $5.3 \pm 0.5 \%$ vs. $2.3 \pm 1.3 \%$ ) and a larger number of longer $\mathrm{TH}$ fiber lengths were observed (data not shown). These results indicate that mature DA neurons were efficiently generated from the FGF8 that was supplied during iNPC generation stages.

\section{Discussion}

Alternative DA neurons can be ideal cell sources for cell replacement therapy for Parkinson's disease. To obtain DA neurons in vitro, various cell types and growth protocols have been developed. Recently, direct conversion methods have become one of the most popular approaches because they sidestep the issue of pluripotent stem cells, which is the main problem for cell therapy. On the other hand, reprogramming efficiency of direct conversions is lower than that from other cell sources. In order to improve DA neuron generation efficiency, we treated the culture media with FGF8 during the direct conversion and expansion period. Early period of cluster-forming and iNPC proliferation stages, did not experience an improved proliferation rate when grown in the presence of FGF8; one explanation for this is that FGF2, not FGF8, is actually the significant influencing factor. FGF2 is known to promote the survival and proliferation of neural precursor cells (19). However, the DA neuron differentiation rate with FGF8 contrasted greatly with the rate of without FGF8 conditions. FGF8-treated groups highly expressed $\mathrm{TuJ} 1+, \mathrm{TH}+$, and $\mathrm{TuJ} 1+\mathrm{TH}+/ \mathrm{TH}+$ cells after differentiation. In particular, DA neuron maturation was confirmed by $\mathrm{TH}$ fiber lengths (data not shown). In our work, FGF8 is a morphogenetic factor that was used to understand patterning and maturation of midbrain-type DA neurons.

Unfortunately, other functional markers for DA neurons were not statistically different between the FGF8+ and FGF8 - groups. To explain this, we considered the possibility that absence/presence of shh influences the role of FGF8 in DA neuron generation. Shh is required for numerous developmental processes, including specification of ventral cell types in the central nervous system, such as midbrain DA neurons. shh and FGF8, which are soluble neurotrophic factors, have been shown to regulate the initial stages of DA neuronal development and to specify DA progenitors in the ventral area of the midbrain (20). Here our data strongly implicates FGF8 signaling in the regulation of maturation of iNPC-derived DA neurons in vitro. Further to improve the functionality of DA neurons, we will evaluate the effect of a combination of FGF8 and shh in culture.

\section{Acknowledgments}

This work was supported by the Medical Research Center (2008-0062190), the Basic Science Research Program (2011-0008952) through the National Research Foundation of Korea (NRF), funded by the Ministry of Science, ICT, \& Future Planning and Hanyang University (201400000000578).

\section{Potential conflict of interest}

The authors have no conflicting financial interest.

\section{References}

1. Vierbuchen T, Ostermeier A, Pang ZP, Kokubu Y, Südhof TC, Wernig M. Direct conversion of fibroblasts to functional neurons by defined factors. Nature 2010;463:10351041

2. Caiazzo M, Dell'Anno MT, Dvoretskova E, Lazarevic D, Taverna S, Leo D, Sotnikova TD, Menegon A, Roncaglia P, Colciago G, Russo G, Carninci P, Pezzoli G, Gainetdinov RR, Gustincich S, Dityatev A, Broccoli V. Direct generation of functional dopaminergic neurons from mouse and human fibroblasts. Nature 2011;476:224-227

3. Pfisterer U, Kirkeby A, Torper O, Wood J, Nelander J, Dufour A, Björklund A, Lindvall O, Jakobsson J, Parmar M. Direct conversion of human fibroblasts to dopaminergic neurons. Proc Natl Acad Sci USA 2011;108:10343-10348

4. Kim J, Efe JA, Zhu S, Talantova M, Yuan X, Wang S, Lipton SA, Zhang K, Ding S. Direct reprogramming of mouse fibroblasts to neural progenitors. Proc Natl Acad Sci USA 2011;108:7838-7843

5. Thier M, Wörsdörfer P, Lakes YB, Gorris R, Herms S, Opitz T, Seiferling D, Quandel T, Hoffmann P, Nöthen MM, Brüstle O, Edenhofer F. Direct conversion of fibroblasts into stably expandable neural stem cells. Cell Stem Cell 2012;10:473-479

6. Sheng C, Zheng Q, Wu J, Xu Z, Sang L, Wang L, Guo C, Zhu W, Tong M, Liu L, Li W, Liu ZH, Zhao XY, Wang L, Chen Z, Zhou Q. Generation of dopaminergic neurons directly from mouse fibroblasts and fibroblast-derived neural progenitors. Cell Res 2012;22:769-772

7. Kim J, Su SC, Wang H, Cheng AW, Cassady JP, Lodato MA, Lengner CJ, Chung CY, Dawlaty MM, Tsai LH, Jaenisch R. Functional integration of dopaminergic neurons directly converted from mouse fibroblasts. Cell Stem Cell 2011;9:413-419

8. Liu X, Li F, Stubblefield EA, Blanchard B, Richards TL, Larson GA, He Y, Huang Q, Tan AC, Zhang D, Benke TA, Sladek JR, Zahniser NR, Li CY. Direct reprogramming of human fibroblasts into dopaminergic neuron-like cells. Cell Res 2012;22:321-332

9. Crossley PH, Martin GR. The mouse Fgf8 gene encodes a family of polypeptides and is expressed in regions that di- 
rect outgrowth and patterning in the developing embryo. Development 1995;121:439-451

10. Partanen J. FGF signalling pathways in development of the midbrain and anterior hindbrain. J Neurochem 2007;101: $1185-1193$

11. Ornitz DM, Xu J, Colvin JS, McEwen DG, MacArthur CA, Coulier F, Gao G, Goldfarb M. Receptor specificity of the fibroblast growth factor family. J Biol Chem 1996;271: 15292-15297.

12. Tsang $M$, Dawid IB. Promotion and attenuation of FGF signaling through the Ras-MAPK pathway. Sci STKE 2004; 2004:pe17

13. Lunn JS, Fishwick KJ, Halley PA, Storey KG. A spatial and temporal map of FGF/Erk1/2 activity and response repertoires in the early chick embryo. Dev Biol 2007;302:536-552

14. Lee SH, Lumelsky N, Studer L, Auerbach JM, McKay RD. Efficient generation of midbrain and hindbrain neurons from mouse embryonic stem cells. Nat Biotechnol 2000;18: 675-679

15. Tanaka A, Kamiakito T, Hakamata Y, Fujii A, Kuriki K, Fukayama M. Extensive neuronal localization and neurotrophic function of fibroblast growth factor 8 in the nervous system. Brain Res 2001;912:105-115

16. Park CH, Kang JS, Yoon EH, Shim JW, Suh-Kim H, Lee $\mathrm{SH}$. Proneural bHLH neurogenin 2 differentially regulates
Nurrl-induced dopamine neuron differentiation in rat and mouse neural precursor cells in vitro. FEBS Lett 2008;582: 537-542

17. Lim MS, Chang MY, Kim SM, Yi SH, Suh-Kim H, Jung SJ, Kim MJ, Kim JH, Lee YS, Lee SY, Kim DW, Lee SH, Park $\mathrm{CH}$. Generation of dopamine neurons from rodent fibroblasts through the expandable neural precursor cell stage. J Biol Chem 2015;290:17401-17414

18. He XB, Yi SH, Rhee YH, Kim H, Han YM, Lee SH, Lee H, Park CH, Lee YS, Richardson E, Kim BW, Lee SH. Prolonged membrane depolarization enhances midbrain dopamine neuron differentiation via epigenetic histone modifications. Stem Cells 2011;29:1861-1873

19. Hajihosseini MK, Dickson C. A subset of fibroblast growth factors (Fgfs) promote survival, but Fgf-8b specifically promotes astroglial differentiation of rat cortical precursor cells. Mol Cell Neurosci 1999;14:468-485

20. Cooper O, Hargus G, Deleidi M, Blak A, Osborn T, Marlow E, Lee K, Levy A, Perez-Torres E, Yow A, Isacson O. Differentiation of human ES and Parkinson's disease iPS cells into ventral midbrain dopaminergic neurons requires a high activity form of SHH, FGF8a and specific regionalization by retinoic acid. Mol Cell Neurosci 2010;45:258266 